and children, scattered in about 280 farms, where they kept cattle, goats, sheep, and horses, perhaps raised a few poor crops of little account, and hunted bears, reindeer, and seals. There is no need to recall the history of these settlements, how trade with Europe gradually ceased and how the Norsemen had entirely disappoared when late in the sixteenth century communications with Greenland were reopened.

Recent Danish rcsearches at Herjolfsnes, near Cape Farewell, have discredited the old belief that the colonies disappeared either by Eskimo extermination or by fusion with the Eskimo races. It now seems clear, at lcast as regards Oesterbygd, that the Norse race maintained its racial purity and did not ' go native'. The general reluctance of the Nordic races to mix with widely divergent stock was as noticcable then as it has been in later centuries. Examination of skeletons in the churchyard of Herjolfsnes reveals the interesting facts that while clothes and ornamonts, in graves of the fifteenth century, show little trace of Eskimo influence, the skeletons all show signs of rickets or other malformations and stunted growth, but no sign of racial mixture with the Eskimo. There is also a very high proportion of remains of infants and young people. Evidently, therefore, the Norsc colonies, at least Oesterbygd, perished by exhaustion. Even if the climate were changing for the worst during the existence of these coloniesand such a change is by no means proved-there is no reason to suppose that the habitual meat diet failed. The cessation of communications with Europe cannot have affected the diet of the colonists to any great extent. The King's Mirror, describing conditions when the colonies were prosperous, notes that most of the settlers did not know what bread was. And what else could they get from Europe to vary thcir meat diet?

The conclusion is, therefore, that the Norse colonists in Greenland died out for want of new blood, or, in other words, that they were not acelimatised to their Arctic home. From this it might be argued that even the Nordics can never colonise the Arctic. Certainly no other race from temperate climates is likely to try, since the Nordics alone show that distaste for gregariousness and that capacity for enduring solitude which are essential qualities for the task. We may even grant them a greater measure of physical enterprise and love of wandering than other people.

The Greenland experiment is not, however, a sure criterion of Nordic unsuitability for the Arctic. The pastoral settlement, which is suggested, will be a slow colonisation, in which natural selection will have some say. 'Those suited will remain, others will move away or perish. But the colonists will not be cut off from the world : they will be in close touch with it. New blood will contimually flow in their veins, so that the unchecked course of natural selection which operated in the old isolated Norse colonies and killed out the more nervous and imaginative type, a type that is least adapted to the Arctic, will not have free play. There is no reason why the race should become impoverished by the elimination of its most progressive element. Even though a diet solely of meat has proved wholcsome enough in the case of Eskimo and some explorers, it will not be necessary for the Arctic colonists to subsist on it entirely: transport facilities will bring every variety of food to their doors. If the Norsemen suffered from insufficiency of certain ingredients in their diet, a similar fate will not be the lot of the colonists of the future. If they died out by lack of new blood and continual inbreeding, the Arctic settilers of the future will be able to avoid that disaster.

Such is the legitimate forecast, as I see it, of the outer rim of the Arctic of the future with its prosperous, though scattered, colonists of pastoral interests, and its fur farms here and there supplying high-priced Arctic furs in limited numbers. But the settlement must wait until the pressure of population on the world's resources is even greater than it is to-day. The remoter parts, those without rich tundra and the ice-covered seas and lands, must remain deserts, visited only by roving hunters and occasional explorers. In short, I see a shrinking of the Arctic wildernesses, but never their disappearance.

\title{
The Structure of Silicates. ${ }^{1}$
}

\section{By Prof. W. L. BraGG, F.R.S.}

$\Lambda \mathrm{T}$ a time then the fundamental conceptions $A$ of the structure of matter are being changed so rapidy, when every six months witnosses the birth of a new analytical method of dealing with the very foundations of our physical science, the study of the crystal patterns of silicates must seem a trivial matter. Yet similar studies have played their part in the extraordinary development of physics in the last decade, and I hope that the refinement of our methods of analysis, such as is represented by the present examples, will in turn prove to be of use.

The results of the particular investigations which I propose to describe are interesting in themselves 1 Discourse delivered at the Royal Institution on Friday, May 20. because the silicates form so large a proportion of the earth's solid orust, and certain artificial forms are so largely used for technical purposes. I think, however, that it is right to stress another aspect of this study. We are trying to improve the technique of the X-ray examination of solid bodies, to increase the resolving power of our instruments so that we can see finer detail and deal with more complicated structurcs. It is at present a tedions and difficult task to discover how the atoms are arranged in these bodies; even when some cxperience in handling them has been obtained, one has to devote much time and concentration to each particular case. Yet every solution makes the next problem casier to attack, and when we look

No. 3020 , VoL. 120$]$ 
back on the last few years' progress, I think a very real increase in power of analysis is evident as the result of the efforts of many workers in this field.

It is this advancement of technique in which, personally, I am particularly interested. In trying to improve our instrument we examine with it from time to time a new type of solid body-these silicates being an example-and we describe what we see. I am not competent to discuss the discoveries we make; I can only hope that the casting of light at a new angle may be useful to those who have made a life-long study of these particular types of compound. I feel that my main contribution must be a demonstration of what knowledge it is possible to attain by careful X-ray examination.

The silicates present a highly interesting series of problems for X-ray analysis. The numerous crystalline forms have been carefully studied because of their importance to the mineralogist, and they show most interesting relationships and wide variation in composition. It is estimated that oxygen, silicon, aluminium, and iron by themselves compose about 87 per cent. of the earth's crust, and if we add four other elements, calcium, sodium, potassium, and magnesium, they amount together to 98 per cent. These are the elements that build up the compounds we are considering, and their relative proportions are a reflection of the fact that most of the earth's crust is composed of compounds of metals with silicon and oxygen.

The silicates occur as solid bodies, the atoms of which are arranged in crystalline patterns. These patterns are often very complex, and it would be difficult to attack them by general methods unless some guiding line could be followed through the intricate maze. Such a guiding line may perhaps be found in the peculiar part which the oxygen atoms play in building up the structure. Not only are the oxygen atoms the most numerous, but also they appear to be the most bulky of the units of which the pattern is woven, so that their predominant size and number make them force the other atoms to conform to certain simple and characteristic arrangements of oxygen atoms which we find occurring again and again as an underlying motif, throughout the range of such silicates as have yet been analysed. A few simple examples may help to illustrate this point.

Four spheres, packed together as tightly as possible, assume a tetrahedral arrangement with one sphere standing on three others (Fig. 1a). Six spheres when packed together take up a form where three of them lie on top of three others (Fig. 1b). Alternatively we may regard this arrangement as four spheres at corners of a square, with one above and one below this square (Fig. 1c), the second arrangement being identical with the first regarded from a different view point.

These very simple groupings of oxygen atoms, with an atom of some other element at the centre of the group, occur again and again in the silicates and in many other compounds. In many cases the group not only has a characteristic shape, but also a characteristic size, the distance between the oxygen atoms having a value of about $2 \cdot 5 \AA$ A.U. to
$2 \cdot 7$ A.U. In the list of common elements given above it is only sodium, calcium, and potassium which appear to break up the regularity of this group, and to force the oxygen atoms apart if placed at the group centre. The other elements appear to fit comfortably into the interstices of the oxygen grouping. Since there is a common distance throughout between oxygen atoms, certain atoms of one group can at the same time form part of the next group, and so a continuous structure is built up which may be thought of as a pattern of oxygen atoms with the metal and silicon atoms in its interstices.

This predominance of the oxygen atoms greatly simplifies the analysis of the structures, and makes it easier to visualise the relationships between different types. All these bodies build up a crystalline pattern repeated again and again to space. Now the simplest types of pattern are those such as children are taught to make, when blocks of the same shape and size, but coloured differently, can be stacked together in geometrical designs. The silicates present rather a fascinating analogy to these kindergarten patterns, the oxygen atoms being the

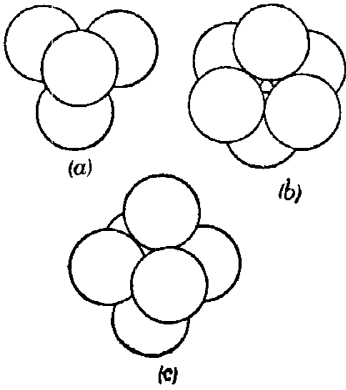

FIG. 1.-Groups of four, and of six, oxygen atoms. Such or one of the metals at the centre, are repeated indefinitely in the silicate structure. groups, with atoms of silicon

blocks and the other atoms the colouring agent. It is as if a complex pattern were embroidered by the other atoms upon a simple underlying fabric of oxygen atoms.

The two types of group, four-fold and six-fold, illustrated in Fig. 1 are composed of oxygen atoms equidistant from their neighbours. We have seen that they may be regarded as spheres compressed into the smallest possible space. Such an arrangement can be continued indefinitely, and if it is done regularly one or other of two characteristic groupings of spheres is the result. These are the wellknown forms of cubic and hexagonal close-packing.

This close-packing of the oxygen atoms is a very simple arrangement, and it is interesting to find that a number of silicates are based on it. Its existence in a silicate can be surmised by noting how much volume there is to each oxygen atom in the whole structure. If the oxygen atoms are packed together closely, with $2 \cdot 7$ A.U. between their centres, it is easy to calculate that each atom occupies a minimum volume of $14\left(\AA . \mathrm{U}^{3}{ }^{3}\right.$ ). (If magnesium and iron are present, they expand this volume slightly by an amount for which allowance can be made.) Further, the refractive index, if ideal close-packing exists, must not be less than $1 \cdot 7$, as the oxygen atoms have a high refractivity.

Using these tests, it appears probable that certain compounds are based on one of the forms of closepacking, and we have examined some of these cases. The close-packing of the oxygen atoms is, however, exceptional, and although in most compounds the

No. 3020, VoL. 120] 
fourfold and sixfold groups form the basis of the pattern, this pattern may be of an open type. The various forms of silica, to the investigation of which the Royal Institution has made so large a contribution, are beautiful examples of open patterns built of the four-fold groups, and other examples of these lace-work open patterns have been analysed. The closely woven patterns have been chosen for de-
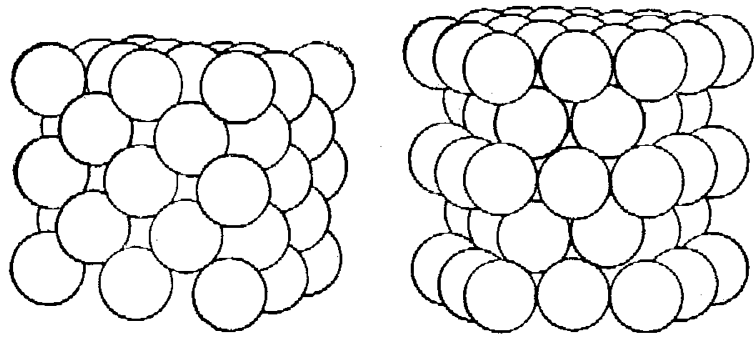

FIt. 2.-Spheres in cubic and hexagomal closest-packing.

scription here because their basis is the more simple.

In order to understand these frameworks of oxygen atoms, with metal atoms packed in: the interstices, it is necessary to bear in mind some of the geometrical laws of pattern-making. If a repeated pattern be formed by stacking together blocks of the same size and shape, but different in colour, the unit of the pattern will be composed of a whole number of blocks. It is always possible to outline the pattern with a series of unit cells, each of which just contains one complete example of the pattern and no more. The unit cell may be a large and distorted one if the pattern is complex, but it must always obcy one condition. If one corner is placed at the centre of a block, all the other corners will also be at centres. The crystals which are based on one of the close-packed arrangements of oxygen atoms must have a unit cell related to the close-packed arrangement in this way.

Disthene or cyanite, $\mathrm{Al}_{2} \mathrm{SiO}_{5}$, is an example of such a crystal. Its unit cell could not well be more irregular. Its edges, and the angles between them, are all unequal, as shown in Fig. 3.

Yet its high refractive index $(1 \cdot 72)$ and small volume per oxygen atom $\left(15 \cdot 0 \AA\right.$ A. U. $\left.{ }^{3}\right)$ hint that the oxygen atoms are in one of the forms of close-packing. An X-ray examination has proved this to be the case. The packing turns out to be of the cubic type, and the way the disthene cell and the cubicaliy arranged oxygen atoms 'fit together' is shown in Fig. 3. The cell of disthene contains twenty oxygen atoms, and the cell outlined in the right-hand figure contains exactly twenty closepacked spheres. This very complex pattern of disthene has to be woven into a basis of twenty oxygen atoms, since a multiple of five is demanded by the chemical formula. The irregular disthene cell is the way chosen by Nature of blocking out suitable groups of twenty oxygen atoms from the very simple cubic structure.

When the scattering of X-rays by the crystal is cxamined, the close-packed arrangement of oxygen atoms shows up strongly. We can consider the effect on the X-rays as composed of that due to the oxygen atoms on one hand, combined with that due to the atoms of metal and silicon on the other hand. The former leads to a simple and intense diffraction pattern, to be expected from a straightforward cubic face-centred lattice. The aluminium and silicon atoms, which form a complex embroidcry on a large scale woven into the oxygens, give a complex diffraction pattern within that due to the oxygen atoms alone. Fig. 4 illustrates the point.

The complex inner pattern contains the information necessary to tell us where the aluminium and silicon atoms are. It is a difficult matter to unravel its story, but it is by no means so formidable as it would have been had we not known that the oxygen atoms are nearly in this simple arrangement, and that the aluminium and silieon atoms are somewhere within the four-fold or six-fold groups of oxygen atoms.

As another example of this pattern-weaving, the series of compounds $\mathrm{Mg}_{2} \mathrm{SiO}_{4}, \mathrm{MgO}_{2} \mathrm{H}_{2}\left(\mathrm{Mg}_{2} \mathrm{SiO}_{4}\right)_{2}$, $\mathrm{MgO}_{2} \mathrm{H}_{2}\left(\mathrm{Mg}_{2} \mathrm{SiO}_{4}\right)_{2}, \mathrm{MgO}_{2} \mathrm{H}_{2}\left(\mathrm{Mg}_{2} \mathrm{SiO}_{4}\right)_{4}$ may be examined. The dimensional relationships between these crystals (the chondrodite series) have long

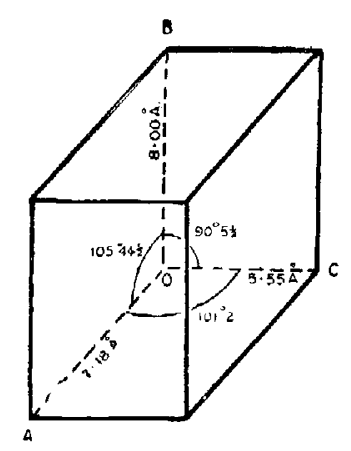

(a)

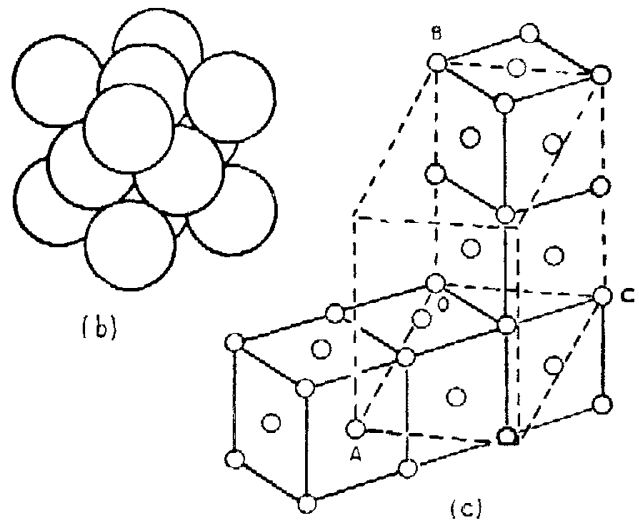

(c)

FIG. 3.- $(a)$ shows the unit cell of disthene; $(b)$ is a portion of the array of spheres in cubic closelacking; (c) shows to the same scale a more cxtended portion of this array, the centres of the spheres alone being indicated. The unit cell of disthene is also a unit cell (containing twenty points) of the cubic lattice;
in length and direction in $(a)$ and $(a)$.

aroused interest. If we measure the unit colls of the compounds we find that two axes, outlining one face, remain constant throughout all four crystals. The thickness of the cell measured perpendicularly to this face increases in regular steps in the last three compounds, as if blocks of magnesium silicate were being added on in a regular way. With the aid of $\mathrm{X}$-rays this process can be followed out in detail, and some finer points of it are not without interest. All the compounds prove to be based on hexagonal close-packing, and with 
the aid of this guiding feature, Mr. West and Mr. Taylor, who have been working on these crystals in my laboratory, have, in my opinion, succeeded in elucidating the approximate positions of all the
That part of it which is magnesium silicate is arranged exactly like the pure magnesium silicate shown in Fig. 5a. The layers of hydroxide cement together the blocks of magnesium silicate. In order to outline the unit cell of any of these patterns, we join up four points in the pattern which .are exactly alike. The diagram will show that the measured unit cells, shown by dotted lines, are exactly those cells which satisfy these conditions. Chondrodite, $\mathrm{MgO}_{2} \mathrm{H}_{2}$ $\left(\mathrm{Mg}_{2} \mathrm{SiO}_{4}\right)_{2}$, must have a slanting cell, the next compound, humite, a long rectangular one, and the last, clinohumite, again a slanting cell. We were surprised in making our X-ray examination to find such a curious difference

FIG. 4.-Rotation photograph around $b$ axis of disthene (right) compared with ideal rotation photograph around cube edge for close-packed atoms (left).

atoms in these complex patterns. Their results are shown in Fig. 5.

These patterns are very formidable unless one has made a special study of them. However, the figures may perhaps make clear the main points. We have to explain the way in which the unit cell varies in size from compound to compound, and we have also to explain a curious complication. Whereas $\mathrm{Mg}_{2} \mathrm{SiO}_{4}$ and $\mathrm{MgO}_{2} \mathrm{H}_{2}$ $\left(\mathrm{Mg}_{2} \mathrm{SiO}_{4}\right)_{3}$ have a rectangular cell (orthorhombic), the other two compounds are built on a slant with the type of symmetry called monoclinic. The blocks are not clapped directly on top of each other, but are stepped sideways. It is fascinating (to the enthusiast) to see how naturally the results follow from the arrangements shown in the figure.

The circles in Fig. 5 represent the oxygen atoms which form the framework on which our whole structure is based. Two layers of such atoms are shown, representing two sheets of spheres packed closely, one lying on the other. Some of the oxygen atoms are linked together to form a group $\mathrm{SiO}_{4}$ with a silicon (not shown) at its centre. These groups are shown as tetrahedra in the diagram, and six or three edges of each tetrahedron are drawn, depending on whether its apex is turned towards or away from the observer. The magnesium atoms are left out of the diagram for the sake of simplicity; the shaded pairs of oxygen atoms are to be labelled ' $\mathrm{OH}$,' since they must belong to the hydroxyl groups.

Each crystal is a series of alternate strata of magnesium silicate and magnesium hydroxide. in the shape of the unit cell between humite on one hand and chondrodite and clinohumite on the other hand. When the pattern was put together, however, it was clear that such a difference

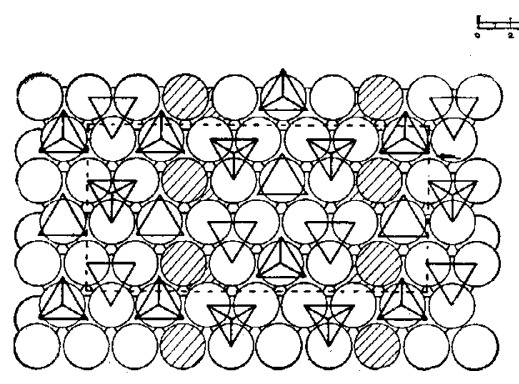

c. Humito

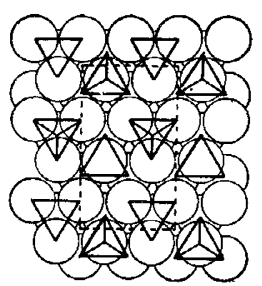

a, Olivine
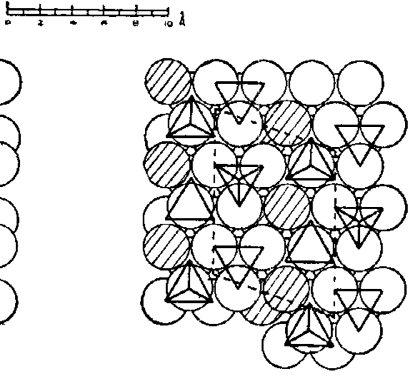

b. Chondrodite

FrG. 5.-Atomic arrangement of the chondrodite series of minerals (after Taylor and West). Two layers of oxygen atoms in hexagonal close-packing are shown, projected on the plane (100) of each crystal. The $a$ axes of the crystals are perpendicular to the plane of the diagram, and are practically identical for all the crystals. The diagram shows the identity

followed naturally from the relative numbers of silicate and hydroxide strata.

Though very few examples of silicates have yet been analysed, the temptation to draw conclusions from them is irresistible. The most curious feature about the natural silicates is the immense variety in composition which occurs within one and 
the same mineral species. Stupendous chemical formulie have to be assigned in order to explain even approximately the relative proportions of the different elements in some well-known types.

It seems to me that the position becomes clearer when we consider the compounds as an embroidery of the metal atoms upon an oxygen framework. We may compare the oxygen framework to the steel girder system of a large forro-concrete building in course of construction, which is intended to be divided into sets of flats. Before the girder system is filled in, its configuration is very simple indeed. Then certain blocks of it are partitioned off into sets of rooms, each comprising a flat; these flats are the moro complex units of pattern in the crystalline structure. The arrangement of the rooms in each flat corresponds to the selection in our oxygen framework of certain spaces in which to put the metal atoms. We can go one step further, and rent our flats to families of slightly different composition, so that a census of the whole building shows a bewildering proportion of types of inhabitants difficult to represent by a definite family formula. This is really the state of affairs with which the chemist is confronted when he attempts to give a formula to many of the silicates.

Some of the very earliest structures which were analysed caused us to revise our ideas of what was meant by the "molecule' of the chemist. In sodium ohloride there appear to be no molecules represented by $\mathrm{NaCl}$. The equality in numbers of sodium and chlorine atoms is arrived at by a chess. board pattern of these atoms; it is a result of geometry and not of a pairing-off of the atoms. This is, of course, not universally true, for this absence of the molccule in solids is in general only found in inorganic compounds. It would appcar, however, that the silicates are of this non-molecular type, and that in sceking to assign formulæ to them, and to the hypothetical acids of silicon on which they are based, it should be borne in mind that they are really extended patterns. The relative numbers of their constituent atoms are characteristic of the extended pattern, and essentially a result of their solid state, so that it is doubtful whether a grouping of the atoms into molecules has in this case a meaning. It will be very interesting to see what further light the $\mathrm{X}$-ray results can cast on the relationships in this fascinating series of compounds.

\section{Obituary.}

Prof. Rutolf Magnus.

THROUG the W fifty-three years, of Rudolf Magnus, professop of pharmacology in the University of Utred the world of science loses one who had for sofe years past been one of the outstanding figures in experimental medicine. At this moment there is nearing completion in Utrecht, and to be opened this autumn, a fine new Institutc of Pharmacology, given by the Rockefeller Foundation with the primary object of widening the opportunity for and increasing the influence of his investigations. These, for some eighteen years past, have issued in an imposing series from the picturesque laboratory which Magnus had evolved, with great ingenuity, from a small monastic plague-hospital. The many who knew and admired him had thought of him carrying on his brilliant work for at least two further decades, and touching a growing circle with his ideas and his enthusiasm, under material conditions at last worthy of his genius.

Magnus is most widely known for the work which he, with a brilliant group of collaborators, has carried out during the past eighteen years on the functions of the central nervous system, and, in particular, on the reflex mechanisms involved in the assumption and maintenance of bodily posture, in normal relation to the earth's surface. He had spent several periods in British laboratories, with Schafer in Edinburgh, with Langley in Cambridge, and with Sherrington in Liverpool. From the last-mentioned association he received the stimulus which resulted in this best known and most important phase of his work. In Utrecht he had invaluable co-operation in this line of investigation from De Kleijn, Raademaker, and others; Dr. de Kleijn has won eminence as an otological surgeon without relinquishing his position as assistant in Magnus's department of pharmacology. The results of this work have appeared in a long series of papers, and have been embodied by Magnus in a masterly monograph on "Körperstellung," published in 1925. In the same year he gave a brilliant summary of the work in the Croonian Lecture to the Royal Society.

This work on the central nervous system, which attracted physiologists and neurologists from all over the world to Utrecht, represents, however, only one side of Magnus's scientific activity. Beforc his appointment to the Utrecht chair, he had been for a long term of years attached to the department of pharmacology at Heidelberg under Gottlieb. During this period he published a series of important papers of a more definitely pharmacological intercst. Among the items of this earlier work may be mentioned his introduction of the method of studying the activity of mammalian unstriated muscle, by the simple technique of suspending the organ containing it in warm, oxygenated Locke-Ringer solution. Magnus, unlike some of the many who have since used it, always had clearly in view the true value and limitations of the method, and even in recent years his pupils were still busy with its application to isolated layers of the intestinal wall, with results leading to revision of his earlicr conclusions as to the neurogenous nature of intcstinal rhythm. By the use of this method also, in the Utrecht period, he and his pupils reached important conclusions concerning the significance of choline as a natural hormone of intestinal activity.

It is an astonishing fact, indeed, that Magnus made his Institute a centre of world interest in experimental neurology, without relaxing his 